\title{
Reportagem
}

\section{Os desafios da redução da pobreza e da desigualdade}

Por Larissa Mamed Hori e Juliana Silveira de Souza

A desigualdade de renda no Brasil vem declinando de forma contínua, ao mesmo em tempo que se verifica redução do nível de pobreza. Entre 2001 e 2004, o coeficiente de Gini (medida utilizada para calcular a desigualdade de distribuição de renda) passou de 0,59 para 0,56 (quanto mais alto o coeficiente, maior a desigualdade). A melhoria decorrente dessa queda é, além disso, mais bem percebida pela população mais pobre. "A média geral de crescimento da renda per capita entre 2001 e 2005 foi de $1 \%$ ao ano. Para os $10 \%$ mais pobres da população foi de $8 \%$, mas, para os 10\% mais ricos, o crescimento foi de $0,9 \%$ ao ano", explicou Ricardo Paes de Barros, pesquisador do Instituto de Pesquisa Econômica e Aplicada (IPEA), no seminário internacional " $\mathrm{O}$ desafio da redução da desigualdade e da pobreza", que ocorreu no IPEA, em Brasília, nos dias 30/11 e 01/12, e contou com a participação de pesquisadores da Argentina, Chile, Colômbia e México. Isso, de acordo com Paes de Barros, é o que reforça a sensação de estagnação econômica sentida pela parcela mais rica da população.

Apesar da queda do coeficiente de Gini de aproximadamente quatro pontos percentuais, o País ainda apresenta alto grau de desigualdade: o $1 \%$ mais rico da população apropria essencialmente a mesma

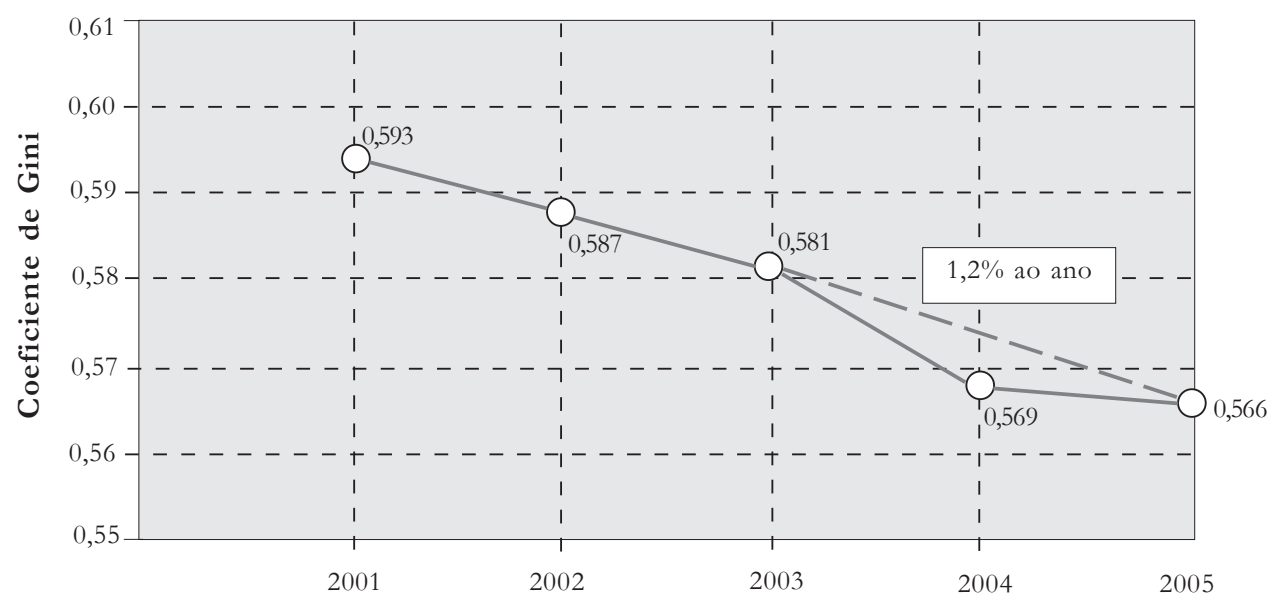

Gráfico 1: Queda da desigualdade de renda no Brasil- 2001-2004 
parcela de renda dos $50 \%$ mais pobres ${ }^{1}$. "Nessa velocidade, precisamos de mais 25 anos de redução contínua da desigualdade para chegarmos à média de desigualdade em que se encontra a Tunísia hoje", ressaltou Paes de Barros. Em 2001, o coeficiente de Gini do Brasil era de 0,593, enquanto a Tunísia, no ano anterior, apresentava índice de 0,398. "A continuidade é absurdamente importante para garantir a redução da desigualdade”, afirmou.

\section{Determinantes da queda}

No "menu" das medidas responsáveis pela queda da desigualdade e da pobreza no Brasil nos últimos dez anos, Sergei Soares, também pesquisador do IPEA, destacou quatro dimensões: a educação, O trabalho, a previdência social e a assistência social.

\section{Educação}

$\mathrm{Na}$ área de educação, Soares chamou a atenção para alguns programas, entre eles o Fundo de Manutenção e Desenvolvimento da Educação Básica (Fundeb), o Financiamento Estudantil (FIES) e o Programa Universidade para Todos (ProUni).

Apesar da expansão do ensino fundamental, a continuidade dos estudos permanece como desafio. Dados da PNAD/IBGE mostram que o número de alunos que freqüentaram o ensino fundamental, em 2003, foi aproximadamente 34 milhões, enquanto o número de alunos do ensino médio, no ano seguinte, não chegou a 9 milhões, enfatizando a importância de políticas educacionais de combate à desistência escolar.

Reynaldo Fernandes, presidente do INEP/MEC, sugeriu, no seminário, que o Programa Bolsa Família poderia ampliar sua atuação, passando a beneficiar famílias com jovens de até 17 anos (idade de conclusão do ensino médio). Para ele, é um erro olhar a educação de forma separada, priorizando apenas o ensino fundamental. "É necessário expandir o investimento no ensino médio e superior. $O$ gasto com ensino superior hoje é alto porque há poucos alunos", destacou.

\section{Trabalho e previdência social}

A Previdência Social também vem contribuindo para combater as desigualdades.

Segundo Sergei Soares, em 2004, $30,6 \%$ da população estava abaixo da linha da pobreza. Se não fosse a Previdência, esse percentual seria de $42,1 \%$, diferença que representa 22,4 milhões de pessoas.

\section{Programas de Governo na área de Educação}

Fundeb: assiste a crianças da educação infantil ao ensino médio, com o objetivo de diminuir a desigualdade educacional. Para 2006, a previsão de valores foi de 50,7 bilhões de reais, o que corresponde a 48,1 milhões de alunos da rede básica de ensino.

FIES: favorece o acesso de estudantes de baixa renda ao ensino superior por meio do financiamento das mensalidades. O programa surge em decorrência do fato de, hoje, $67 \%$ dos alunos de ensino superior ingressarem em universidades particulares.

ProUni: atua por meio do fornecimento de bolsas estudantis integrais ou parciais aos estudantes de baixa renda. Como pré-requisito, o ProUni exige a obtenção de nota no ENEM ( Exame Nacional do Ensino Médio) do ano anterior, o que privilegia a continuidade dos estudos dos alunos recém graduados do ensino médio. 
A Previdência também contribui para proteger a queda do beneficiário à condição de pobreza nos casos de acidente, gravidez e invalidez, entre outros.

O salário mínimo também desempenha um dos papéis fundamentais no combate à pobreza. "Ele tem caráter de política de trabalho, e assim impacta $\mathrm{O}$ mercado de trabalho, de política assistencial e de política previdenciária, já que indexa o piso do Regime Geral da Previdência”, explicou Soares. O valor do salário mínimo, em termos reais, dobrou em 12 anos. Nos últimos quatro anos, o aumento foi de 50\%. De acordo com a PNAD 2005, há 152,7 milhões de pessoas no País em idade ativa, ou seja, com dez anos ou mais e com renda, mesmo que em forma de benefício. Desse total, 38,2 milhões têm rendimento de até um salário mínimo, dos quais 3,5 milhões estão no Norte $(8 \%)$ e 16,2 milhões no Nordeste (41,8\%). No Sudeste, são 12,4 milhões de trabalhadores que recebem até um salário mínimo (32,6\%).

\section{Assistência social}

$\mathrm{Na}$ dimensão da política de assistência social $^{2}$, Soares destacou os programas de transferência direta de renda, como o Beneficio de Prestação Continuada (BPC) e o Programa Bolsa Família. O BPC, implementado em 1995, é direcionado ao idoso e ao portador de deficiência, atingindo um total de 2,398 milhões de beneficiários. O Programa Bolsa Família, por sua vez, é destinado a famílias pobres (com renda mensal, por pessoa, de $\mathrm{R} \$ 60,01$ a $\mathrm{R} \$ 120,00)$ e extremamente pobres (com renda mensal, por pessoa, de até $R \$ 60,00)$ e tem como objetivo principal o alívio imediato da pobreza. $\mathrm{O}$ Bolsa Família unificou quatro programas já existentes, o Bolsa Escola, o Bolsa Alimentação, o Auxílio Gás e o Cartão

\section{Alguns programas do Sistema Público de Emprego}

Abono salarial: assegurado aos que recebem até dois salários mínimos de remuneração mensal dos empregadores que contribuem para o programa PISPasep. No exercício de 2001/02, a taxa de cobertura era de $94,41 \%$ dos beneficiários.

Seguro desemprego: fundamentado em preceito constitucional. Seu objetivo é prover assistência financeira e temporária ao trabalhador dispensado involuntariamente. $\mathrm{O}$ valor a ser recebido pelo beneficiário é baseado no último vínculo empregatício, podendo ser pago em até cinco parcelas.

Programa Nacional de Estímulo ao Primeiro Emprego (PNPE): visa combater a pobreza e a exclusão social por meio da integração de políticas públicas de emprego e renda com políticas de investimentos voltadas para a geração de empregos. Tem como público-alvo jovens entre 16 e 24 anos. O número de postos de trabalho gerados pelo programa é de, aproximadamente, 15.260 e o quantitativo dos jovens com contratos efetivados pelas empresas foi de 5.620.

Programa Geração de Emprego e Renda (PROGER): conjunto de medidas especiais de crédito para financiar o empreendedor que deseja investir no próprio negócio. Tem como beneficiários os trabalhadores informais, as micro e pequenas empresas, as cooperativas e associações de produção formadas por micro ou pequenos empreendedores, os professores que desejarem adquirir equipamentos de informática e as pessoas físicas que queiram comprar material para construção habitacional.

Programa Nacional de Microcrédito Produtivo Orientado (PNMPO): concede crédito às pessoas físicas e jurídicas empreendedoras de atividades produtivas de pequeno porte (com renda bruta anual de $R \$ 60$ mil). Busca incentivar, assim, a geração de emprego e renda aos chamados microempreendedores populares. 
Alimentação e atinge hoje 11,1 milhões de famílias.

O Programa exige dos beneficiários algumas condicionalidades vinculadas à educação - matrícula dos filhos de 6 a15 anos na escola, com freqüência mínima de $85 \%$ - e vinculadas à saúde - vacinação, acompanhamento pré-natal e acompanhamento infantil". "A nova geração de programas sociais, que exigem contrapartida, é algo que veio para ficar", comentou Renato Baumann, diretor-geral da CEPAL no Brasil.

O impacto dos programas de transferência de renda sobre a redução da desigualdade e da pobreza é significativo. As transferências governamentais (pensões e aposentadorias, o Beneficio de Prestação Continuada e o Programa Bolsa Família) respondem, de acordo com Ricardo Paes de Barros, por 80\% da queda verificada nos últimos anos.

\section{Contexto internacional}

Argentina, Chile, Colômbia e México também vêm adotando iniciativas nacionais de combate à desigualdade e a pobreza. Destacam-se, a seguir, algumas delas.

\section{Programa Jefes de Hogar - Argentina}

O programa constitui um conjunto de políticas ativas dirigidas a promover a inserção dos beneficiários no mercado de trabalho. Surgiu em 2002 como conseqüência da crise econômica enfrentada pelo país. Um levantamento do programa mostra que, em outubro de 2005, mais de 8,5 mil beneficiários inseriram-se no mercado de trabalho. O maior aproveitamento ocorreu em Buenos Aires: dos 537.872 beneficiários, 3,9 mil foram incorporados em empregos permanentes. No âmbito do programa, há incentivos legais destinados ao empregados, que estabelecem, por exemplo, a redução de contribuições trabalhistas.

De acordo com o Instituto Nacional de Estadísticas y Censos da Argentina (Indec) ${ }^{4}, 31,4 \%$ dos habitantes dos principais aglomerados urbanos do país estão abaixo da linha da pobreza. Abaixo da linha de indigência estão 11,2\%. A Argentina está entre os países da América Latina de pobreza moderada. "Tivemos dois grandes fracassos em termos de redução da desigualdade e da pobreza", ressaltou o pesquisador Leopoldo Tornarolli, do Centro de Estúdios Destributivos, Laborales, y Sociales da Universidad de la Plata. "Um é o fracasso de crescimento. Em 30 anos, a média de crescimento foi de menos de $2 \%$ ao ano. Se tivesse sido de 4\% a.a., a taxa de pobreza estaria hoje em 5\%", afirmou. Entre 1990 e 2005, a América Latina teve redução geral de $20 \%$ da pobreza enquanto, na Argentina, a queda foi de 10\%. De 1993 a 1999, apesar do crescimento econômico, o índice de pobreza aumentou 12 pontos percentuais na Grande Buenos Aires. "O outro é o fracasso distributivo. Há 30 anos, a Argentina estava no mesmo nível do Uruguai [um dos países da AL com menor índice de pobreza e desigualdade]. Hoje, somos marcadamente diferentes", disse. Na opinião de Tornarolli, o Programa Jefes de Hogaré positivo, mas necessita intensificar

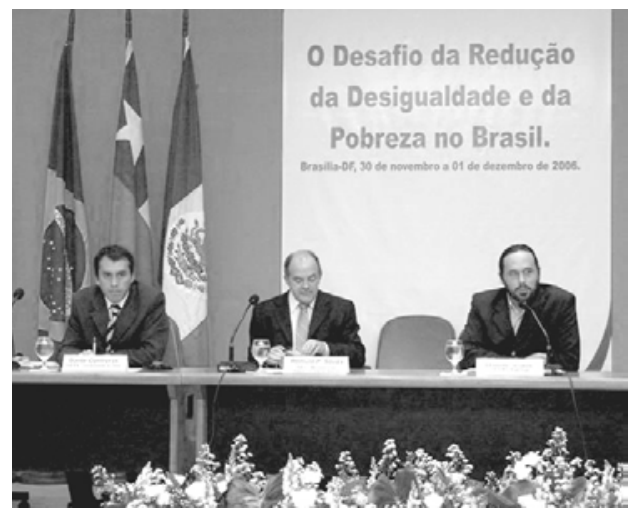


o esforço distributivo. "O desenho de uma política para combater a pobreza é diferente daquele destinado a combater o desemprego", ressaltou.

\section{Chile Solidario}

O Chile é um dos países que obteve êxito na redução da pobreza. Em 1987, a porcentagem da população considerada pobre era de 45,1\%; em 2003, esse valor baixou para 18,8\%. De acordo com Dante Contreras, da Faculdad de Economía y Negócios, 80\% dessa redução deveu-se à expansão econômica registrada entre 1987 e 1998. "O crescimento foi homogêneo para todos", destacou. Uma pesquisa realizada com 4.060 domicílios entre 1996 e 2001, que captou os efeitos da crise asiática (1998-2000), mostrou, por outro lado, a vulnerabilidade das famílias chilenas no médio e longo prazo. "Há grande mobilidade posicional nos oito primeiros décimos da população. Assim, se uma família deixou de ser pobre hoje, não quer dizer que não será pobre no futuro", afirmou Contreras. "O Chile é menos pobre, mas ainda é um pobre", disse.

O país implementou o programa Chile Solidario, que visa apoiar as famílias mais pobres. O programa é uma proposta do Ministério do Planejamento (Mideplan) e tem como objetivo organizar uma rede de serviços e programas sociais de apoio às famílias de extrema pobreza, aos idosos com mais de 65 anos que vivem sós e aos moradores de rua, bem como reduzir a pobreza ao nível dos países avançados em dez anos. O Chile Solidario, em primeiro lugar, convida as famílias para participar de uma rede pública de proteção social. O programa apresenta três componentes. Pelo Programa Puentes (apoio psicossocial), as famílias comprometem-se a trabalhar, durante dois anos, com um profissional da área social, denominado "apoio familiar", que propõe ferramentas que possibilitarão às famílias construir seus próprios caminhos de superação. O governo concede um "aporte solidario", de caráter decrescente, entregue à mulher que chefia a família ou à cônjuge do chefe de família. O valor inicial desse crédito é de 10.500 pesos chilenos (equivalente a $\mathrm{R} \$ 42,30)$ para os seis primeiros meses ${ }^{5}$. Outro componente do programa é a concessão dos Subsidios Monetarios como o Subsidio Único Familiar (SUF), para famílias com crianças menores de 18 anos, Pensão Assistencial da Velhice (PASIS), para os maiores de 65 anos e Subsídio de Água Potável (SAP). Por fim, os beneficiários do Chile Solidario, têm assegurado acesso prioritário a esses subsídios e a outros programas sociais nas áreas de saúde, educação, justiça e trabalho, seja de entidades públicas ou privadas.

\section{Colômbia}

A Colômbia é um país com elevado grau de desigualdade, tendo, no ano de 2002, o seu índice de Gini medido em $0,57 \%{ }^{6}$. Em uma pesquisa realizada pela ONG Planeta Paz, da Noruega, 67\% da população total disse considerar-se pobre (60\% da população urbana e $88 \%$ da população rural) e $8 \%$ da população disse já ter deixado de fazer as três refeições por dia, pelo menos uma vez por semana, por falta de recursos financeiros.

A alta concentração de terra - na zona rural, 35,8\% dos proprietários detém 0,4\% da área total, enquanto 0,06\% detém 53\% e, na zona urbana, $26 \%$ dos proprietários detém 3,2\%, enquanto $0,6 \%$ detém 58\% da área total - e o paramilitarismo agravam essa situação.

Como forma de enfrentamento desse cenário, tem-se desenvolvido políticas sociais que priorizam a descentralização da 
gestão, a focalização e a incorporação de novos atores como bancos internacionais.

$\mathrm{Na}$ área da saúde, destacou Adriana Rodrigues, pesquisadora do Centro de Investigaciones para el Desarrollo, da Universidade Federal da Colômbia, há 17 milhões de pessoas que não são afiliados ao sistema e não recebem, assim, assistência médica. "Há um desperdício significativo porque o sistema de saúde tem hoje um número muito grande de intermediários", disse a pesquisadora. Um dos focos da política nessa área é a atenção primária à saúde, tendo como objetivos principais a atenção sanitária e a atenção integral. Outro aspecto é a segurança alimentar, problema decorrente da redução na produção per capita de alimentos. O país apresenta um dos maiores índices de subnutrição infantil da América Latina. Para tanto, está em fase de desenvolvimento um sistema de abastecimento alimentar.

\section{Oportunidades - México}

A partir de 1995, o México registrou taxas de crescimento positivas e significativas em sua economia, apesar das crises de 1994-1996 e 2000-2002. O crescimento real anual total do país, no terceiro trimestre de 2005 , foi de $3,4 \%$, enquanto, no terceiro trimestre de 2006, foi de 4,6\%. Apesar disso, a renda média por família não se recuperou e o México apresenta elevado nível de desigualdade (o coeficiente de Gini foi de 0,47 em 2005). Por outro lado, destacou Fernando Cortés, pesquisador do El Colegio de México, cada vez que há uma crise econômica (como em 1984, 1996 e 2002), verifica-se queda na desigualdade.

$O$ pesquisador questiona se isso representaria um indício de um novo modelo econômico ou se as pesquisas estariam enviesadas. "No décimo decil da amostra, não estão os mais ricos do país.
Nele estão os assalariados, técnicos, funcionários públicos e privados e agentes de vendas", alertou Cortés. "É preciso mais pesquisa para averiguar se, nos períodos de crise, essa queda da desigualdade não estaria originando-se da restrição do gasto público, que, além de diminuir o gasto de investimento, reduz o gasto com pagamento de salários", afirmou o pesquisador mexicano.

O governo mexicano vem implementando o programa Oportunidades, que, de forma focalizada, articula os diversos programas nas áreas de educação, saúde e nutrição e busca aliviar as condições de extrema pobreza por meio de transferências monetárias diretas. O Oportunidades atinge hoje cinco milhões de famílias. Mais da metade dos domićlios nele inscritos encontram-se nos oito estados com menor grau de desenvolvimento humano no México.

No âmbito da educação, o programa procurou identificar as causas de abandono escolar e hoje, encontram-se, nos sete estados mais pobres do país, mais de um terço dos bolsistas de educação básica do programa. Como conseqüência, observase aumento do número de crianças pobres que freqüentam a escola ao lado de crianças das famílias mais ricas. Em relação à nutrição, atualmente, o país apresenta índice de $12,7 \%$ de crianças menores de cinco anos e com estatura menor do que a considerada ideal. Em 1999, esse índice era de $17,8 \%$. O programa distribui, gratuitamente, complementos alimentares a crianças e mães beneficiárias. Ele é considerado a principal ferramenta de combate à desnutrição no México, beneficiando $25 \%$ das famílias em todo o país. 


\section{Notas}

${ }^{1}$ Ricardo Paes de Barros, Mirela de Carvalho, Samuel Franco e Rosane Mendonça. Uma das principais causas da queda recente na desigualdade de renda brasileira. Texto para discussão 194, maio de 2006. Disponível em: <www.uff.br/econ/> . Acesso em: 07 dez. 2006.

${ }^{2}$ São objetivos da assistência social: a proteção à família, à maternidade, à infância, à adolescência e à velhice; o amparo às crianças e adolescentes carentes; a promoção da integração ao mercado de trabalho; a habilitação e reabilitação das pessoas portadoras de deficiência e a promoção de sua integração à vida comunitária; a garantia de um salário mínimo de benefício mensal à pessoa portadora de deficiência e ao idoso que comprovem não possuir meios de prover a própria manutenção ou de tê-la provida por sua família. (art. $2^{\circ}$ Lei Orgânica da Assistência Social)

3 “Desafios da dimensão política intersetorial para o enfrentamento das desigualdades sociais". Jeni Vaitsman, Departamento de Avaliação e Monitoramento da Secretaria de Avaliação e Gestão da Informação- MDS. Disponível em: <www.abrasco.org.br>. Acesso em: 08 dez. 2006.

${ }^{4}$ Dados disponíveis em <wwww.indec.gov.ar>. O levantamento refere-se à Encuesta Permanente de Hogares, que se aplica em 28 aglomerados urbanos argentinos, que correspondem a $70 \%$ da população urbana e $60 \%$ da população total do país.

${ }^{5}$ Valores do Aporte Solidário: 10,5 mil pesos chilenos ( $\$$ 42,31) para os seios primeiros meses, 8 mil pesos chilenos ( $\mathrm{R} \$ 32,24)$ entre o sétimo mês e um ano, 5,5 mil pesos chilenos $(\mathrm{R} \$ 42,31)$ entre os 13 e 18 meses.

${ }^{6}$ Dado obtido em: Indicadores sociales: educación, salud, pobreza, tecnología, genero y aspectos de gobernalidad y democracia. Documento elaborado a partir do Informe de Desarrollo Humano 2002, PNUD. Disponível em: <www.comunidadandina.org/estadisticas>. 